\title{
DECLARACIONES ESTATUTARIAS ¿DE DERECHOS? UN ANÁLISIS A LA LUZ DE LAS SSTC 247/2007 Y 31/2010*
}

\author{
ENRIQUETA EXPÓSITO GÓMEZ \\ Profesora Titular de Derecho Constitucional \\ Universitat de Barcelona
}

\begin{abstract}
SUMARIO
I. Punto de partida: las declaraciones de derechos son un contenido estatutario lícito desde la perspectiva constitucional

II. Contenido de las declaraciones estatutarias de derechos

III. La naturaleza de los derechos contenidos en los Estatutos de Autonomía: ¿derechos subjetivos, expectativas o principios que deben regir la actuación de los poderes públicos autonómicos?

IV. El desenlace. de la originalidad del estatuyente a la creatividad del Tribunal Constitucional: la desactivación normativa de las cartas estatutarias de derechos
\end{abstract}

La inclusión, con distinto contenido, alcance y significación, de cartas de derechos en las reformas de los Estatutos de la Comunidad valenciana y, muy especialmente, en el de Cataluña —que culminan con su aprobación en el año 2006 — , provocó una abundante literatura jurídica en la que, esencialmente, se confrontaban los argumentos a favor y en contra de su admisión como un contenido constitucionalmente posible de las normas estatutarias ${ }^{1}$. Sin

* El presente trabajo se inserta en el marco del proyecto financiado por el Ministerio de Ciencia e Investigación DER2009-12921 sobre «Estado Autonómico y democracia: los derechos de participación en los Estatutos de Autonomía».

1 No por conocido debe dejar de recordarse el debate iniciado en el año 2006, en el nº 78 de la Revista Española de Derecho Constitucional por L. Ma DíEz PICAZO con «¿Pueden los Estatutos de Autonomía declarar derechos, deberes y principios?». Interrogante que fue contestado por F. CAAMAÑO en el n ${ }^{\circ} 79$ (2007) de la misma revista con «Si, pueden (Declaraciones de Derechos y Estatutos de Autonomía)» y replicado por L. Ma Díkz PICAZO en el n 81 (2007): «De nuevo sobre las declaraciones estatutarias de derechos: respuesta a Francisco Caamaño». Contribuyeron a este debate otros autores entre los que, sin ánimo de ser exhaustiva, puede citarse a 
embargo, pese a la intensidad y enjundia del debate, no puede afirmarse que tuviera muchas consecuencias en las reformas estatutarias en curso. Todas ellas incluyeron en su articulado - con mayor o menor extensión, detalle o sistematicidad ${ }^{2}$ - declaraciones de derechos, deberes y/o principios rectores de la actuación de los poderes públicos autonómicos que, en algunos supuestos, se acompañaban —inspirándose en el Estatuto catalán- de un sistema propio de garantías ${ }^{3}$.

En este contexto, en el que también las posiciones de algunos partidos políticos e instituciones del Estado estaban confrontadas, la apelación a la intervención del Tribunal Constitucional era más que previsible. La primera se produce en relación con el Estatuto de la Comunidad valenciana con la adopción de dos sentencias casi consecutivas: la 247/2007, de 12 de diciembre y la 249/2007, de 13 de diciembre ${ }^{4}$. La segunda tenía como objeto el nuevo Estatuto de Autonomía de Cataluña sobre el que ya se han emitido las sentencias que han resuelto los diversos recursos de inconstitucionalidad planteados contra el mismo: 31/2010, de 28 de junio; 46 y 47/2010, de 8 de septiembre; 48/2010, de 9 de septiembre; 49/2010, de 29 de septiembre, 37 y 138/2010, de 16 de diciembres.

De todas las anteriores, centraré mi análisis en las SSTC 247/2007 y 31/2010 — con alguna puntual referencia a la STC 137/2010 — por ser las que contienen el núcleo central de la argumentación en torno a este contenido estatutario. Debe advertirse, sin embargo, que los procedimientos resueltos por las dos primeras sentencias no tenían como objeto de impugnación ni el Título II del reformado Estatuto de la Comunidad valenciana («De los derechos de los valencianos y valencianas») ${ }^{6}$ ni el Título I del nuevo Estatuto de Cataluña («De los derechos, deberes y principios rectores) ${ }^{7}$, el cual sí que es censurado

Ferreres, V., Bliglino, P. Y Carrillo, M., Derechos, deberes y principios en el nuevo Estatuto de Autonomía de Cataluña, CEPC, Madrid, 2006 o el propio M. CARrILlo, «Los derechos: un contenido constitucional de los Estatutos de Autonomía», Revista Española de Derecho Constitucional, nº 80, 2007.

2 Teniendo en cuenta estos criterios le diferenciarían tres categorías de Estatutos. A la primera pertenecen los Estatutos catalán, andaluz, castellano leonés y, en cierta medida, el retirado proyecto de Castilla-La Mancha, por ser aquéllos que contienen una prolija declaración de derechos, de todo tipo con una sistemática muy parecida a la utilizada por la Constitución Española. Un segundo grupo, lo integrarían los Estatutos de la Comunidad Valenciana, de las Illes Balears y de Aragón, lo cuales, aun conteniendo estas Cartas de derechos, son más selectivas y sintéticas. Una singularidad de los Estatutos valenciano y balear es la remisión que ambas normas realizan a una futura Carta de Derechos Sociales. Y un tercer grupo lo integra, el Estatuto de Extremadura. En esta propuesta normativa, siguiendo el ejemplo del retirado proyecto de Estatuto de Canarias, declara en su art. 6 que los derechos fundamentales de los extremeños son los establecidos en la Constitución, pudiendo, solicitar de los poderes públicos autonómicos la efectividad «de otros derechos contenidos en este Estatuto o en la legislación, especialmente el de participar en los asuntos públicos directamente o por medio de representantes y el de petición».

3 Es el caso de los Estatutos de Andalucía, Castilla y León.

4 En ellos se resolvían los recursos de inconstitucionalidad planteados, respectivamente, por los gobiernos de las Comunidades Autónomas de Aragón y de Castilla-La Mancha.

5 Las sentencias enumeradas resuelven los recursos de inconstitucionalidad interpuestos por casi un centenar de diputados del Grupo parlamentario Popular y los Consejos de Gobierno de las Comunidades Autónomas de Aragón y de las Illes Balears, de la Comunidad valenciana; de la Región de Murcia, del Defensor del Pueblo y de la Comunidad Autónoma de La Rioja, respectivamente.

6 El Gobierno de Aragón sólo recurre el art. 17.1 del reformado Estatuto de la Comunidad Valenciana.

7 De los cuarenta artículos que integran este Título II, los diputados recurrentes sólo cuestionan la conformidad a la Constitución de doce de ellos. 
in totum en el recurso de inconstitucionalidad presentado por el Defensor del Pueblo. Lo anterior, sin embargo, no ha sido obstáculo para que el Tribunal se haya pronunciado con carácter general sobre las cartas estatutarias de derechos en las dos primeras sentencias ${ }^{8}$, dando respuesta a las genéricas alegaciones de los recurrentes ${ }^{9}$, mientras que en la última de ellas, la impugnación de la totalidad del Título I del Estatuto catalán es resuelta con una mera remisión a lo argumentado en las dos anteriores.

La premisa de la que se parte es de la aceptación de que los Estatutos pueden contener cartas de derechos — como se examinará en el apartado I de este trabajo- Con esta declaración, el Tribunal Constitucional parece haber zanjado el debate abierto en la doctrina y en amplios sectores de la política. Sin embargo, la detenida lectura de los fundamentos jurídicos de las citadas sentencias plantea una ulterior pregunta: ¿tienen algún valor las cartas de derechos contenidas en los Estatutos de Autonomía? A este interrogante se dará respuesta abordando dos cuestiones distintas aunque complementarias. La primera de ellas —objeto de análisis en el apartado II — hace referencia al contenido que pueden tener estas declaraciones estatutarias: qué derechos pueden ser proclamados en los Estatutos de Autonomía, qué relación tienen o pueden tener estos derechos con los derechos constitucionales o con aquellos otros proclamados en normas internacionales y, en definitiva, si podemos hablar de la existencia o no de «nuevos» derechos. La segunda — tratada en el apartado III — se centra en la verdadera naturaleza de estos derechos estatutarios: si acogen auténticos derechos subjetivos o meras expectativas de derechos o simplemente si, bajo la apariencia de un derecho, se encierran pautas de actuación para los poderes públicos autonómicos. La hipótesis que se tratará de evidenciar es que la li-

8 La STC 247/2007, para G. CÁMARA, al formular una doctrina de alcance general, se presenta como «anticipatoria de futuros pronunciamientos». Rasgo que también está presente en la STC 31/2010 en la que, según G. Pisarello, se contienen «disquisiciones teóricas, casi doctrinales». Ver, CÁmara, G., «Los derechos estatutarios no han sido tomados en serio. (A propósito de la STC 247/2010, de 12 de diciembre, sobre el Estatuto de Autonomía de la Comunidad Valenciana)», Revista Española de Derecho Constitucional, n 85, 2009, pág. 287 y Pisarello, G., «Drets i garanties jurisdiccionals en la sentència 31/2010 sobre l'Estatut d'Autonomia de Catalunya», Revista Catalana de Dret Públic. Especial Sentència sobre l'Estatut, julio 2010. Por el momento, está disponible en la dirección electrónica: http://www10.gencat.net/eapc_revistadret/recursos_interes/especial\%20estatut/documents\%20especial\%20estatut/document.2010-07-15.7236299341/ca.

9 El Gobierno aragonés atribuye al reconocimiento de derechos en los Estatutos de Autonomía una quiebra de los principios de unidad e igualdad acogidos en los arts. 138.2 y 139 de la CE y de la competencia estatal del 149.1.1 CE. Tampoco a su juicio, esta declaración constituye un contenido propio de la norma estatutaria, especialmente cuando los derechos en ella proclamados no tengan relación alguna con los derechos proclamados en el Título I de la CE ni deriven de las competencias autonómicas. Para los diputados populares, además de imputar al Estatuto catalán un desmesurado afán por emular a la Constitución con la incorporación de esta carta de derechos, esta regulación estatutaria invade ámbitos reservados a la Constitución y no tiene conexión con la reserva estatutaria. Realizada esta consideración previa, los argumentos que esgrimen se ponen en relación con las distintas categorías de derechos contenidas en este Título I del Estatuto de Autonomía de Cataluña. Así, en relación con los derechos y libertades fundamentales, sólo podrían ser aceptados en la medida que fueran una mera reiteración de lo ya contemplado en la Constitución. Cualquier contenido innovador habría de conducir a su nulidad: en tanto que derechos fundamentales existe una reserva de Constitución para ser proclamados y de ley orgánica para ser regulados. Por lo que se refiere a los derechos socioeconómicos y los principios rectores su existencia y desarrollo dependerán de las competencias de la Comunidad Autónoma: en la medida que estemos ante una competencia plena, el Estatuto podrá completar su regulación; pero cuando a la Comunidad Autónoma le corresponda una competencia compartida, las leyes estatales de carácter básico serán las únicas que puedan delimitar el contenido básico del derecho en cuestión. 
citud constitucional de este nuevo contenido estatutario viene acompañada de una contrapartida: su desactivación normativa.

\section{PUNTO DE PARTIDA: LAS DECLARACIONES DE DERECHOS SON UN CONTENIDO ESTATUTARIO LÍCITO DESDE LA PERSPECTIVA CONSTITUCIONAL}

La Constitución no alude, ni expresa ni implícitamente, a estas cartas de derechos como uno de los contenidos necesarios, adicionales o posibles de los Estatutos de Autonomía. Ahora bien, que no lo prevea no significa que lo prohíba: dependerá de si éstas aparecen como un complemento «adecuado por su conexión» a los contenidos que son propios de la norma estatutaria por expreso mandato Constitucional. Y este acomodamiento, demás, «ha de entenderse referido a la función que en sentido estricto la Constitución encomienda a los Estatutos, en cuanto norma institucional básica que ha de llevar a cabo la regulación funcional, institucional y competencial de cada Comunidad Autónoma.» (STC 247/2007, FJ 12 in fine). En consecuencia, los Estatutos pueden acoger derechos siempre y cuando éstos vayan referidos bien a «aspectos centrales o nucleares de las instituciones que regulen», bien a las «competencias que atribuyan en los ámbitos materiales que constitucionalmente les corresponden» (STC 247/2007, FJ 6 6 ${ }^{10}$. El Tribunal aboga, de este modo, por una lectura flexible y actualizada en el tiempo del art. 147 de la $\mathrm{CE}^{11}$, en perfecta sintonía con la concepción del Estatuto como Norma institucional básica del autogobierno de la Comunidad Autónoma.

Estos condicionamientos son confirmados en la sentencia 31/2010 — y, por remisión a ésta, en la posterior STC 137/2010 - en la que el Tribunal explicita una ulterior condición para la aceptación constitucional de los Títulos estatutarios relativos a los derechos: deben respetar los derechos fundamentales proclamados en la Constitución y en otras normas internacionales en la materia suscritas por el Estado español (FJ 16). Ambas son afirmaciones que referidas al Estatuto enjuiciado pueden calificarse de superfluas en la medida que, como el propio Tribunal reconoce, son prescripciones ya exigidas por el art. 37 del Estatuto de Autonomía de Cataluña. Sólo adquiere un sentido pleno si la extrapolamos a otros Estatutos que no acompañan su declaración de derechos de una cláusula similar.

10 Para el magistrado R. RodrígueZ ArRIBAs el señalado en el texto es uno de los argumentos que le permiten rechazar este nuevo contenido estatutario. En su opinión, la admisión de derechos vinculados a las competencias cambia la función constitucional del Estatuto ya que en vez de limitarse a atribuir competencias a las Comunidades Autónomas, lo que hace es ejercitarlas de forma anticipada. Ver el voto particular a la STC 247/2007, FJ 3 in fine.

11 Para F. LóPEz MENudo debe tenerse muy presente que dado que todas las Comunidades Autónomas han ido regulando y creando, a través de su normativa, derechos y deberes «resulta bien difícil eludir esta imponente realidad y negar, de plano, que esa ejecutoria no pueda quedar plasmada en la norma institucional básica de la Comunidad Autónoma cuando ha llegado la ocasión de hacerlo». En «Los derechos sociales en los Estatutos de Autonomía», Administración de Andalucía. Revista Andaluza de Administración Pública, n 73, 2009, págs. 132-133. Una idea parecía ya la avanzaba M. L. BALAGUER en su trabajo «Reformas estatutarias y reconocimiento de derechos», Revista General de Derecho Constitucional, n 3, 2007, pág. 8. 
Identificado el contexto de recepción de los derechos en el Estatuto, el Tribunal concretará, además, los rasgos que los caracterizan: «Lo decisivo para pronunciarse sobre su legitimidad constitucional será, en cada caso, si los mandatos en ellos comprendidos vinculan exclusivamente al poder público catalán y, naturalmente, si sólo pretenden hacerlo en el marco de sus competencias» (STC 31/2010, FJ 16). Son, por tanto, derechos que, en la medida que constituyen la vertiente subjetiva de las competencias que las instituciones, deben proyectarse necesariamente sólo en y frente a estos mismos poderes autonómicos.

El anterior es un análisis que se lleva a cabo en unos parámetros estrictamente objetivos: se admiten los derechos en los Estatutos en la medida que son un complemento a los contenidos mínimos y necesarios que la Constitución remite a la norma institucional básica de las Comunidades Autónomas.

Como contrapartida, el Tribunal rehúye el análisis de la significación de este conjunto de disposiciones desde una perspectiva subjetiva, la de los ciudadanos beneficiarios y titulares de los derechos proclamados en el Estatuto de Autonomía ${ }^{12}$. Éste es un planteamiento que emerge sólo tímidamente en la sentencia 247/2007 cuando el Tribunal, al recordar que si bien los Estatutos de Autonomía pueden «regular aspectos complementarios a los señalados [por la Constitución] tanto en su dimensión material como organizativa», manifestaba con un especial énfasis: «y más en un aspecto que guarda relación con las condiciones de vida de los valencianos y con las competencias de la Comunidad valenciana» en la materia (FJ 19). Ésta es una tesis que, sin embargo, no es desarrollada en la posterior STC 31/2010

La anterior constituye, a mi entender, una omisión plenamente consciente y deliberada ${ }^{14}$. Obedece a un propósito manifiesto: romper con la pretendida aspiración de hacer del Estatuto una suerte de Constitución territorial ${ }^{15}$. Se consolida, demás, su naturaleza de norma básica de la Comunidad Autónoma plenamente objetiva cuya función, en el ordenamiento constitucional, se justifica por su contenido institucional y, sobre todo, competencial. Con respecto a éstos, cualquier otro contenido se presenta como meramente accesorio y desprovisto de toda

12 C. VIVER afirmaba que «hay pocas cuestiones más propias de una norma institucional básica de una comunidad política que el reconocimiento de derechos de sus miembros frente a sus órganos de autogobierno». En «L'Estatut de 2006», Activitat parlamentària, n 10, 2006, págs. 42-43.

13 Concretamente, en ésta puede apreciarse, con claridad, cómo el Tribunal rehuye entrar a examinar la vertiente subjetiva de los derechos estatutarios sometidos a su enjuiciamiento. Sólo entra a valorarla para negar o rechazar explícitamente algunas facultades que para el titular de ese posible derecho pudieran derivarse. Por ejemplo, cuando examina el art. 20 del Estatuto de Autonomía de Cataluña, el Tribunal identifica en la mayor parte de sus contenidos concreciones del derecho a la vida del art. 15 de la CE o del principio del art. 10.1 de la CE, negando explícitamente que de esta proclamación estatutaria se infiera un hipotético derecho a la muerte asistida o a la eutanasia. En otras ocasiones, la identificación implícita de un derecho subjetivo —y no un simple mandato- sirve para hace depender su efectividad de una ley estatal. Así sucede en relación con «el derecho a dejar constancia de la voluntad para el caso de no poder manifestarla en el momento de recibir tratamiento médico» (art. 15 del EAC). El Tribunal, sin entrar a calificar si de este enunciado estatutario se deriva un derecho subjetivo, es contundente en negar que este enunciado pueda afectar al derecho fundamental a la vida para, seguidamente referirse a la obligación que genera para el personal sanitario «en los términos que establecen las leyes» (FJ 19).

14 En el mismo sentido, Cámara, G., «Los derechos estatutarios no han sido tomados en serio...», ob. cit., pág. 291.

15 Muñoz Machado, S., «El mito del Estatuto-Constitución», en Ortega Álvarez, L. (Dir.), La reforma del Estado Autonómico, CEPC, Madrid, 2005, págs. 65-84. 
virtualidad para mutar esa naturaleza plenamente objetiva de la que goza el Estatuto. Empeño que va a resultar esencialmente útil, además, a la hora de determinar el verdadero alcance jurídico de las disposiciones de estos Títulos estatutarios, como se analizará.

\section{I.1. QUE NO QUIEBRA EL PRINCIPIO DE IGUALDAD DE DERECHOS Y OBLIGACIONES DE LOS ESPAÑOLES EN TODO EL TERRITORIO ESTATAL}

Es sabido que la actuación del legislador autonómico en relación con los derechos no afecta al principio de igualdad. Como recuerda el Tribunal en la STC 247/2007, el art. 139.1 CE no impide a este legislador la regulación de determinados principios o enunciados que atribuyan verdaderos derechos subjetivos a los ciudadanos de la respectiva Comunidad Autónoma. En este sentido, la estructuración descentralizada del poder «se proyecta sobre los ciudadanos a través de las potestades que la Constitución atribuye, precisamente, a los diversos entes de naturaleza política, potestades que se ejercen en la esfera de la ciudadanía en la que sí opera el principio de igualdad imponiendo ciertos límites a la acción de los poderes públicos» (STC 247/2007, FJ 4.c). Límites que, según el propio Tribunal, pueden afectar al alcance del ejercicio del principio de autonomía sin que, por ello, se produzca una desvirtuación del mismo. El principio de igualdad sustancial no puede confundirse, por tanto, con el de uniformidad u homogeneidad absoluta en todo el territorio (STC 247/2007, FFJJ 13.a, 14 y 15).

Ahora bien, el nuevo interrogante que tiene que abordar el Tribunal es si ese principio de igualdad sustancial proclamado en el art. 139.1 de la CE impide que sean los propios Estatutos de Autonomía los que contengan tales declaraciones o enunciados, formalizados como derechos estatutarios que vinculen a los poderes públicos (STC 247/2007, FJ 15). A pesar de no pronunciarse de forma expresa, de la STC 247/2007 se deduce que en la medida que son admitidas como uno de los contenidos complementarios no infringe, per se, el principio de igualdad. Algo más explícito se muestra en la STC 31/2010 al afirmar que, del conjunto de disposiciones que con la proclamación de derechos «resulta, naturalmente, un principio de diferenciación que no puede confundirse con la desigualdad o el privilegio proscritos por los arts. 138.2 y 139.1 CE, pues con ella sólo se abunda en la diversidad inherente al Estado autonómico [...] en tanto que implícita en la pluralidad de ordenamientos que [...] operan sobre ámbitos competenciales diversos en los que se actúan potestades legislativas y gubernamentales propias cuyo ejercicio puede legítimamente condicionarse desde la misma norma que define, en concurso con la Constitución, cada uno de esos ámbitos privativos [esto es, el Estatuto de Autonomía]» (FJ 16 in fine).

A mi juicio, el Tribunal Constitucional recorre un largo camino ${ }^{16}$ para ofrecer una respuesta de perfiles tan difusos. Es la propia Constitución la que permite a las Comunidades Autónomas, a partir de su propios Estatutos, asumir competencias en ámbitos materiales relativos a derechos constitucionales — derechos sobre los que han incidido todos los legisladores autonómicos, sin que por ello se haya entendido quebrantada la igualdad — del art.

16 F. López Menudo también pone de relieve el «esfuerzo innecesario» que realiza el Tribunal en este punto retomando la cuestión de la creación y regulación de derechos por parte del legislador autonómico para «extrapolar las conclusiones al plano e los Estatutos, por cierto, de forma expeditiva». En «Los derechos sociales 
139 de la Constitución. En la medida, además, que estos derechos no son otra cosa que la traducción subjetiva de las competencias asumidas ${ }^{17}$ ¿porqué ese mismo Estatuto que acoge la competencia — en términos objetivos - no puede formular derechos a favor de los ciudadanos —en términos subjetivos ${ }^{18}$ ? ¿Acaso no son estos derechos normas que al conferir una serie de facultades al ciudadano, ordenan y someten, en ese mismo ámbito competencial, el ejercicio de ese poder político ${ }^{19}$ ?

\section{I.2. Y NO AFECTA AL PRINCIPIO DEMOCRÁTICO}

A pesar de no constituir uno de los argumentos principales de los recursos que resuelven las SSTC 247/2007 y 31/2010, sí que adquiere centralidad en las objeciones en las que se fundamenta la impugnación del Estatuto catalán por parte del Defensor del Pueblo. De esta manera, éste viene a asumir como propia la tesis esgrimida por un sector doctrinal que identificaba en la incorporación de derechos en los Estatutos de Autonomía un proceso de petrificación del ordenamiento autonómico: al dotarlos de una extrema rigidez, se vuelven indisponibles para el legislador democrático que ve seriamente restringidas sus facultades de intervención en el ámbito delimitado por estos derechos ${ }^{20}$. Quedan afectadas, según esta tesis, las mayorías parlamentarias futuras y muy limitadas las opciones democráticas del legislador au-

en los Estatutos de Autonomía», cit., pág. 107. Para R. CANOSA UsERA, sin embargo, construye una clara muestra del «empeño del Tribunal Constitucional por sentar una doctrina fundada en su jurisprudencia anterior que pueda ser aplicada a un hecho nuevo»; ver «Preparando una mutación constitucional. Comentario a la STC 247/2007, de 13 de diciembre», Teoría y Realidad Constitucional, nº 22, 2008, págs. 571 y 575.

17 «La incorporación de una carta de derechos en los Estatutos viene a significar la traducción de las competencias materiales que tiene atribuidas las Comunidades Autónomas en espacios hábiles para las relaciones jurídicas y para el reconocimiento de facultades subjetivas a los ciudadanos de las Comunidades Autónomas en el plano normativo superior del ordenamiento de la Comunidad Autónoma». Cita de Castellá, J. M. ${ }^{a}$, «Hacia una protección «multinivel» de los derechos en España. El reconocimiento de derechos en los Estatutos de Autonomía de las Comunidades Autónomas», Boletín Mexicano de Derecho Comparado, nº 20, 2007, pág. 728.

18 En un sentido similar, ver Aparicio Wilhelmi, M. y Pisarello, G., «El reconocimiento de derechos, deberes y principios en los Estatutos de Autonomía: ¿hacia una comprensión multinivel o en red de la protección de los derechos?», El Clip, n 42, 2007 y Tur AusinA, R. y Álvarez Conde, E., Las consecuencias jurídicas de la Sentencia 31/2010, de 28 de junio, del Tribunal Constitucional sobre el Estatut de Cataluña. La sentencia de la perfecta libertad, Aranzadi, Pamplona, 2010, pág. 181.

19 Concretamente, para G. CÁMARA los derechos estatutarios en la medida que aparecen vinculados a las competencias autonómicas constituyen «una técnica de regulación de la forma de ejercicio de aquellas competencias por los poderes autonómicos en relación con la ciudadanía». En el fondo, esta proclamación de derechos evidencia lo que para M. A. APARICIO y M. BARCELó aparece como una «imposible disociación en las actuales democracias entre la posibilidad de ejercicio de un poder político propio y el reconocimiento de derechos». Ver, CámARA, G., «Los derechos estatutarios no han sido tomados en serio...», ob. cit., págs. 276 y 277 (la cita literal es de la pág. 276) y ApAricio, M. A. y BARCELÓ, M., «Los derechos públicos estatutarios», en Aparicio, M. A. (Ed.) y CAstellá, J. M. a Expósito, E. (Coords.), Derechos y principios rectores en los Estatutos de Autonomía, Atelier, Barcelona, 2008, pág. 15.

20 Farreres Comella, V., «Derechos, deberes y principios en el nuevo Estatuto de Autonomía de Cataluña», Derechos, deberes y principios en el nuevo Estatuto de Autonomía de Cataluña, CEPC, Madrid, 2006, págs. 22 y 35. En similares términos se pronuncia MARTínez LÓPEZ-MuÑIz, J. L., «Límites constitucionales generales del contenido de las reformas estatutarias», Revista jurídica de Castilla y León, $\mathrm{n}^{\circ}$ especial: «La reforma de los Estatutos de Autonomía», 2005, pág. 109. 
tonómico. Por tanto más que aumentar el autogobierno, se considera que lo que hacen estas Cartas es precisamente lo contrario, restringirlo ${ }^{21}$.

A todas las anteriores críticas, el Tribunal responde en un sentido negativo. En el FJ 6 in fine de la STC 247/2007 se afirma que como en el caso de las leyes orgánicas, cuya existencia la Constitución ha considerado adecuada al principio democrático, los Estatutos de Autonomía «también podrán establecer con diverso grado de concreción normativa aspectos centrales o nucleares de las instituciones que regulen y de las competencias que atribuyan en los ámbitos materiales que constitucionalmente les corresponden, pues no puede olvidarse que el Estatuto, aprobado como Ley Orgánica, es obra de un legislador democrático y que la regulación que realiza, como se ha dicho, es vehículo de la voluntad de autogobierno de un determinado territorio y expresión de la voluntad del Estado».

Realizada esta consideración de carácter general, el Tribunal concreta que esta limitación ni afectará al legislador estatal ni al autonómico. Al primero, porque una de las características que se predican de los derechos estatutarios es la de vincular sólo a los poderes autonómicos. En consecuencia no se les atribuye capacidad de obligar a los poderes estatales ni, por ello, de afectar el ejercicio de sus competencias.

Sin embargo, por lo que se refiere al legislador autonómico, se recurre a un argumento que, sinceramente, no deja de producir una cierta perplejidad por cómo se concluye. En efecto, en la STC 31/2010 (FJ 17 —reproducido en su literalidad en la STC 137/2010, FJ 5-) se afirma que el Estatuto de Autonomía en tanto que ley orgánica, no puede, «no ya declarar o desarrollar derechos fundamentales o afectar a los únicos que son tales, sino siquiera regular el ejercicio de tales derechos. Podrá hacerlo, en su caso, el legislador autonómico, en tanto que legislador ordinario y de acuerdo con el reparto constitucional de competencias, pero no el legislador (orgánico) estatuyente. De ahí que no haya paradoja alguna en el hecho de que por simple ley autonómica (ley ordinaria) pueda hacerse lo que no cabe en un Estatuto (norma superior a la autonómica). En realidad, no es que pueda hacerse más por ley autonómica; es que se hace cosa distinta, como corresponde en el juego de normas ordenadas con arreglo al criterio de competencia». Más allá de no comprender, ni compartir, la razón por la que se decide, en este ámbito material, definir en términos competenciales la relación entre un Estatuto de Autonomía y una ley autonómica, nuevamente, el Tribunal vuelve a utilizar un razonamiento que no ofrece una respuesta directa a la cuestión planteada.

Este tema, el de la afectación a las futuras mayorías constituía uno de los argumentos menos sólidos para oponerse a este nuevo contenido estatutario y más fácil-

21 Farreres Comella, V., «Derechos, deberes y principios en el nuevo Estatuto de Autonomía de Cataluña», cit., págs. 12, 17 y 23. En un sentido similar, RuIz-Rico RuIz, G., «Derechos sociales y reforma de los Estatutos de Autonomía: el derecho a la vivienda», Nuevas políticas públicas. Anuario multidisciplinar para la modernización de las Administraciones Públicas, nº 2, 2006, págs. 85 y 86. L. Ma DíEz PicAzo se mostraba más categórico al considerar que dotarlos de esta rigidez equivaldría a privar a los ciudadanos por vía estatutaria de algo que tienen garantizado por la vía constitucional: «[... . Si no existieran esas normas estatutarias declarativas de derechos, se aplicaría sólo el Título I de la Constitución y los ciudadanos — o sus representantes— podrían debatir y votar sobre más cosas». Vid. Díez Picazo, L.Mª « «Pueden los Estatutos de Autonomía declarar derechos, deberes y principios?», cit., págs. 71-72. 
mente contestable. Ciertamente, la reforma de un Estatuto de Autonomía exige unas mayorías cualificadas tanto en los Parlamentos autonómicos que inician el proceso, como en las Cortes Generales, además de un referéndum de la población autonómica, en algunos casos. Tiene razón F. CAAMAÑo cuando afirma que «si los derechos fundamentales — refiriéndose a los que la Constitución reconoce - son producto de la democracia de consenso, no se alcanza a comprender por qué otros consensos son perjudiciales para la democracia» ${ }^{22}$. Consensos que, a su vez, abjuran el peligro de convertir meros programas políticos ${ }^{23}$ en declaraciones estatutarias de derechos.

Por otra parte, si como se intuye de las sentencias, los Estatutos de Autonomía son las normas idóneas para transformar en derechos muchos de los contenidos sociales de la Constitución, dotarles de este rango estatutario convirtiéndolos en indisponibles para el legislador autonómico supone conferirles una garantía adicional. De esta forma, estos derechos que tradicionalmente, se han situado en el ámbito de lo que es política y económicamente oportuno, pasan a convertirse en normas preceptivas de la actuación de los poderes públicos autonómicos cuya modificación o supresión requerirá un procedimiento de reforma del propio Estatuto de Autonomía en el que se contienen.

\section{CONTENIDO DE LAS DECLARACIONES ESTATUTARIAS DE DERECHOS}

\section{II.1. Derechos estatutarios y Derechos Fundamentales}

«Derechos fundamentales son, estrictamente, aquellos que, en garantía de la libertad y de la igualdad, vinculan a todos los legisladores, esto es, a las Cortes Generales y a las Asambleas legislativas de las Comunidades Autónomas, sin excepción. Esa función limitativa sólo puede realizarse desde la norma común y superior a todos los legisladores, es decir, desde la Constitución, norma suprema que hace de los derechos que en ella se reconocen un límite insuperable para todos los poderes constituidos y dotado de un contenido que se les opone por igual y con el mismo alcance sustantivo en virtud de la unidad de las jurisdicciones (ordinaria y constitucional) competentes para su definición y garantía. Derechos, por tanto, que no se reconocen en la Constitución por ser fundamentales, sino que son tales, justamente, por venir proclamados en la norma que es expresión de la voluntad constituyente». En estos términos literales se expresa el Tribunal Constitucional en la STC 31/2010 (FJ 16).

Los derechos fundamentales, por tanto, no pueden ser objeto de regulación por los Estatutos de Autonomía. Por otra parte, la ley orgánica que aprueba el Estatuto no es norma idónea para declarar ni desarrollar derechos fundamentales, así como regu-

22 En «Sí, pueden», cit., pág. 39.

23 Se utiliza la expresión que aparece en el trabajo de R. TuR ALsINA, «Los derechos y sus garantías en el Estado Autonómico. Tutela multilevel y Estatutos de Autonomía», en Álvarez Conde, E. y PlazA De Diego, R. (Dirs.), Derecho Público y Administración de la Comunidad de Madrid, Tirant lo Blanch-IMAP, Valencia, 2008, pág. 314. 
lar el ejercicio de tales derechos (STC 31/2010, FJ 17 -reproducido literalmente en la STC de 16 de diciembre de 2010, FJ 5). A lo sumo, éstos pueden ser reproducidos en las disposiciones estatutarias limitándose a «hacer lo que ya se ha hecho en la Constitución» (STC 31/2010, FJ 17). Esta misma tesis aparecía en la STC 247/2007, en la que, sin embargo, el Tribunal llega a reconocer, como ya había advertido en su jurisprudencia anterior, que no es una técnica muy correcta el transcribir en leyes los preceptos constitucionales (FJ 15.d).

Una vez asentada esta premisa, la consecuencia más lógica hubiera sido la de invalidar los preceptos estatutarios que haciendo referencia a un derecho fundamental no se limitaban simplemente a transcribirlo. No obstante, el Tribunal no sólo evita dicha declaración de inconstitucionalidad sino que, además, acepta la posibilidad de que el legislador estatutario vaya más allá de la mera reproducción e incida, de esta manera, en los derechos fundamentales. En la STC 247/2007, estas previsiones estatutarias serán legítimas, desde la perspectiva constitucional, «si, además, guardan relación con alguna de las competencias asumidas por la Comunidad Autónoma, incurriendo en inconstitucionalidad en caso contrario»(247/2007, FJ 15.d). Y en la STC 31/2010 da un paso más y acepta que los derechos estatutarios puedan aparecer como concreciones del contenido de algunos derechos constitucionales: bien al entender que el derecho proclamado en el Estatuto constituye, en su literalidad, una facultad implícita en el derecho fundamental al cual se conecta ${ }^{24}$, bien al interpretar el enunciado estatutario para situarlo en la esfera del derecho fundamental de que se tra$\mathrm{te}^{25}$.

24 Así en los derechos proclamados en el art. 20 Estatuto de Autonomía de Cataluña. En relación con sus contenidos estatutarios el Tribunal se pronuncia en los siguientes términos: por lo que se refiere al tratamiento del dolor y los cuidados paliativos «se compadece con perfecta naturalidad con el derecho fundamental a la vida y a la integridad física y moral (art. $15 \mathrm{CE}$ ) y es, incluso, una consecuencia obligada, por implícita, de la garantía de ese derecho fundamental, al que, por ello, ni contradice ni menoscaba», por lo que respecta al derecho a vivir con dignidad el proceso de la muerte «no es sino una manifestación del derecho a la vida digna y con el mismo alcance que para ese concepto puede deducirse de los arts. 10.1 y $15 \mathrm{CE}$, es decir, sin que necesariamente se implique con ello el derecho a la muerte asistida o a la eutanasia».

25 Esta argumentación se utilizó en los derechos enunciados en los arts. 15.2 (derecho a vivir con dignidad, seguridad y autonomía, libres de explotación, de maltratos y de cualquier tipo de discriminación y derecho al libre desarrollo de su personalidad y capacidad personal) y 21 del Estatuto de Cataluña (derechos y deberes en el ámbito de la educación), en especial en su apartado segundo (el derecho que asista a los padres y madres para que sus hijos reciban la formación religiosa y moral que vaya de acuerdo con sus propias convicciones en las escuelas de titularidad pública, en las que la enseñanza es laica). En relación con el primero de ellos, el Tribunal consideró que no constituía más que «el enunciado redundante de las palabras del art. 10.1 CE y de las declaraciones internacionales de derechos más principales» (STC 31/2010, FJ 18). Por lo que respecta a la segunda de las disposiciones citadas, el Tribunal la declaró su contenido «manifiestamente inocuo en su contraste con los diferentes aparatados del art. $27 \mathrm{CE}$, pues aseguran en idénticos términos el derecho a la educación». Y «la referencia del precepto a que la enseñanza pública «es laica» sólo significa, como se deduce de su tenor literal, que la enseñanza pública no es institucionalmente una enseñanza confiada a las confesiones religiosas, sin perjuicio del derecho de las madres y los padres a «que sus hijos e hijas reciban la formación religiosa y moral que esté de acuerdo con sus convicciones en las escuelas de titularidad pública», como el propio precepto reconoce en términos plenamente respetuosos con el art. 27.3 CE y con el art. 16 CE» (STC 31/2010, FJ 20) 


\section{II.2. ¿QUÉ DERECHOS PUEDEN SER ACOGIDOS EN EL ESTATUTO?}

«Los derechos reconocidos en Estatutos de Autonomía han de ser, por tanto, cosa distinta [a los derechos fundamentales acogidos en la Constitución]. Concretamente, derechos que sólo vinculen al legislador autonómico [...]; y derechos, además, materialmente vinculados al ámbito competencial propio de la Comunidad Autónoma» (STC 31/2010, FJ 16).

Esta exigencia de vincular los derechos al ámbito competencial propio de la Comunidad Autónoma — característica del reconocimiento de derechos por las entidades no estatales, como así demuestra la Carta de Derechos Fundamentales de la Unión Europea-, además de constituir el presupuesto «constitucional» para admitir las cartas de derechos en las normas estatutarias tiene para el Tribunal otra virtualidad: salvaguardar la reserva de Constitución para proclamar derechos. Se alejando, de esta manera, a la norma estatutaria del proceso de reconocimiento y protección «multinivel» que caracteriza a los Estados con una fuerte y consolidada descentralización del poder ${ }^{26}$.

Sin negar las consideraciones anteriores, debe tenerse presente otras finalidades de igual relevancia que, sin embargo, no son consideradas por el Tribunal Constitucional en las sentencias analizadas. En primer lugar, permite cualificar el ejercicio de esas mismas competencias: con la entrada en vigor de las nuevas normas estatutarias se cualifica el ejercicio de la autonomía. Pero también, consolida la visión normativa del Estatuto de Autonomía: reconocer derechos en ámbitos en los que la Comunidad Autónoma no tiene competencia normativa equivaldría a plasmar en los Estatutos normas inefica$\operatorname{ces}^{27} \mathrm{o}$, en el mejor de los casos, programáticas.

Asentado este lecho competencial, los derechos que pueden ser acogidos en un Estatuto de Autonomía no es una cuestión que el Tribunal deje zanjada o perfectamente delimitada ${ }^{28}$.

Una vez «aparcada» la diferenciación apuntada en la STC 247/2001 entre derechos lingüísticos, derechos que se deducían de las facultades de organización autonómica propia y derechos que se conectaban con las competencias autonómicas [FJ $15 \mathrm{~b}$ y c] —y obviando por completo la sistematización de derechos realizada en el Estatuto catalán, de las sentencias analizadas parecen deducirse tres tipos de derechos: derechos que hacen referencia a derechos constitucionales; derechos que se proclaman en relación con las instituciones autonómicas de autogobierno y aquellos otros que puedan derivarse del ejercicio de competencias propias de la Comunidad Autónoma. No obstante, a pesar de ser el anterior el criterio que va a utilizar el Tribunal cuando se refiera a la naturaleza jurídica de estos derechos, es una regla poco útil a la hora de responder al interrogante planteado en el título de este epígrafe: muchos de los derechos estatutarios que van referidos al ámbito de las instituciones y/o vinculados a las competencias autonómicas se presentan, a su

26 Castellá Andreu, J. Ma , «El reconocimiento y garantía de los derechos y libertades en los Estados compuestos. Una visión comparada», en Aparicio, M. A. (Ed.) y Castellá Andreu, J. Ma y Expósito, E. (Coords.), Derechos y libertades en los Estados compuestos, Atelier, Barcelona, 2005, pág. 13.

27 Así Canosa Usera, R., «La declaración de Derechos en los nuevos Estatutos de Autonomía», págs. 88, $103-104$ y 114 .

28 También Tur Ausina, R. y Álvarez Conde, E., Las consecuencias jurídicas de la Sentencia 31/2010..., ob. cit., pág. 181 
vez, emparentados con derechos constitucionales o como concreciones de algunos de sus contenidos.

La cuestión que se plantea, entonces, es determinar si es admisible que los Estatutos proclamen derechos que nada tengan que ver con los derechos constitucionales. Y, en efecto, el Tribunal ha aceptado que en la norma estatutaria puedan proclamarse nuevos derechos (principios o directrices) en ámbitos distintos a los que hacen referencia los derechos constitucionales ${ }^{29}$. No ha facilitado, sin embargo, ninguna ulterior concreción que pudiera resultar útil a los efectos de determinar en qué casos sería legítimo, en el bien entendido que éstos «nuevos» derechos se situaran en el ámbito material definido por las competencias de la Comunidad y respetaran los derechos constitucionales y los derivados de los Tratados y normas internacionales de obligado cumplimiento para el Estado español.

Una de las posibilidades que se apuntan en el recurso de inconstitucionalidad que resuelve la STC 247/2007 es la utilización del art. 10.2 de la CE para la incorporación de «nuevos» derechos que se proclaman en el orden internacional a través de su plasmación estatutaria. El Tribunal es tajante en afirmar que «el mandato del art. 10.2 CE se refiere a los derechos constitucionales». Y, concretamente, por lo que respecta al cuestionado derecho al agua, el Tribunal considera que «los textos internacionales a que se refieren tanto la parte actora como la representación de las Cortes valencianas no pueden entenderse comprendidos entre «los tratados y acuerdos internacionales sobre las mismas materias ratificados por España', a que nos remite el art. 10.2 CE. En efecto, aun admitiendo que podamos estar ante un derecho emergente de tercera generación, es claro que en el momento actual su incipiente gestación se refleja en instrumentos internacionales que no requieren de manifestación expresa de la voluntad de los Estados, por lo que no puede hablarse de la asunción de compromisos concretos al respecto por parte de España» (FJ 20 in fine).

En esta específica cuestión que plantea el interrogante con el que se ha titulado este concreto apartado es perfectamente asumible la ambigua posición del Tribunal al respecto. Un examen de las disposiciones que integran los títulos estatutarios en los que se acogen derechos avala la dificultad de encontrar «nuevos» derechos ${ }^{30}$. En realidad, la «originalidad» de los Estatutos de Autonomía queda reducida a la incorporación de derechos que se formulaban como tales en la jurisprudencia constitucional o en la concreción de algunos derechos constitucionales — actualizando, de esta forma su contenidoo, en definitiva, en la «elevación del rango» de derechos que ya existían en el ordenamiento interno que aparecían en desarrollos normativos de preceptos constitucionales por parte del legislador estatal o autonómicos. Incluso, se advierte, en algunas ocasiones, la intención del estatuyente de «recibir» en el Estatuto derechos que aparecen en documentos o normas internacionales que el Estado ya está obligado a respetar, en especial, la

29 El derecho al agua que proclama el impugnado art. 17 del Estatuto valenciano no enuncia ningún derecho ya regulado en la Constitución: no se identifica con ninguno de ellos, por mucho que su contenido pueda tener agua conexión con la protección del medio ambiente del art. 45 de la CE (STC 247/2007, FJ 18).

30 Un pormenorizado estudio de los derechos contenidos en los nuevos Estatutos de Autonomía es realizado por Expósito, E., «La regulación de los derechos en los nuevos Estatutos de Autonomía», Revista de Estudios Autonómicos y Federales, nº 5, 2007, págs. 172 a 189. 
Carta de Derechos Fundamentales de la Unión Europea ${ }^{31}$ — a la que el Tratado de Lisboa dota de rango de derecho originario-.

Por otra parte, sí parece claro que el Tribunal (STC 31/2010) admite la recepción estatutaria de derechos en los que se concreten otros derechos constitucionales que no tengan la condición de derechos fundamentales. A pesar de no ofrecer ulteriores concreciones se sobreentendería que se acepta que los Estatutos pudieran dar forma expresa de derechos a muchos de los «derechos» sociales o de tercera y cuarta generación que encierran los enunciados de los principios rectores del Capítulo III del Título I de la CE.

\section{LA NATURALEZA DE LOS DERECHOS CONTENIDOS EN LOS ESTATUTOS DE AUTONOMÍA: ¿DERECHOS SUBJETIVOS, EXPECTATIVAS O PRINCIPIOS QUE DEBEN REGIR LA ACTUACIÓN DE LOS PODERES PÚBLICOS AUTONÓMICOS?}

«[B]ajo la misma categoría «derecho» pueden comprenderse realidades normativas muy distintas [...] ya en la propia Constitución bajo el término «derecho» se comprenden tanto verdaderos derechos subjetivos como cláusulas de legitimación para el desarrollo de determinadas opciones legislativas, si bien en ambos casos se trata siempre de mandatos dirigidos al legislador, bien imponiéndole un hacer o una omisión que se erigen en objeto de una pretensión subjetiva exigible ante los Tribunales de justicia; bien obligándole a la persecución de un resultado sin prescribirle específicamente los medios para alcanzarlo y sin hacer de esa obligación el contenido de ningún derecho subjetivo, que sólo nacerá, en su caso, de las normas dictadas para cumplir con ella. Normas, en definitiva, que prescriben fines sin imponer medios o, más precisamente, que proveen a la legitimación de la ordenación política de los medios públicos al servicio de un fin determinado» (STC 31/2010, FJ 16).

A la vista de esta declaración, es del todo oportuno cuestionarse si son estos derechos estatutarios verdaderos derechos subjetivos o, por el contrario estamos en presencia de otro tipo de normas. El Tribunal, con carácter general, aceptaba —en la STC 247/2007-que en estas cartas estatutarias pudieran contenerse derechos subjetivos «dotados de eficacia jurídica directa en los ámbitos concretos en los que la propia Constitución abre tal posibilidad». Pero descendiendo a un plano más concreto, la individualización de estos derechos subjetivos en las normas estatutarias viene cargada de matices. $\mathrm{Y}$ es en este contexto en el que cobra plena operatividad la distinción que parece realizar el Tribunal entre derechos estatutarios que reiteran o concretan derechos constitucionales, derechos «institucionales» y derechos «competenciales» pero no para identificar distintas categorías de derechos, sino para llegar a la conclusión de que los Estatutos sólo pueden dos tipos de derechos: los derechos subjetivos y derechos cuya inmediata virtualidad sería la de operar como mandatos a los poderes públicos ${ }^{32}$.

31 Ibidem, págs. 189-193.

32 Así, Cabellos, M. A., «Drets i garanties jurisdiccionals en la sentència sobre l'Estatut d'Autonomia de Catalunya», Revista Catalana de Dret Públic. Especial Sentència sobre l'Estatut, julio 2010. Por el momento, está 
De esta manera, los derechos subjetivos, para el Tribunal, aparecen claramente en tres supuestos. El primero, cuando «la previsión estatutaria incide en los derechos fundamentales en sentido estricto» — en una directa alusión al art, 23 de la CE- (STC 247/2007, FJ 15.a). Pero también en los casos en los que el Estatuto de Autonomía «concreta» otras prescripciones o derechos constitucionales que no tengan la condición de derechos fundamentales. Y, por último, también en los supuestos en que estos derechos estatutarios se proyecten en el ámbito de las instituciones (conexión directa del art. 147.2 con el art. 152.1 CE). En relación con este último grupo de derechos, el Tribunal entiende que «son los Estatutos, precisamente, la concreta fuente constitucionalmente prevista para dotar de sentido y alcance material a la institución de que se trate con la orientación que cada uno de ellos considere adecuada dentro del marco de la Constitución. De este modo, dichas regulaciones estatutarias, llamadas constitucionalmente a producir una vinculación directa de los poderes públicos de la Comunidad, pueden generar también verdaderos derechos subjetivos» —la cursiva es mía - (FJ 15.b).

Pero, por el contrario, no se llega a iguales conclusiones cuando se refiere a las disposiciones estatutarias que acogen derechos que aparecen vinculados sólo a las competencias. Éstos contenidos, según el Tribunal, «requieren de la colaboración del legislador autonómico, de tal manera que las prescripciones estatutarias relativas a este último ámbito, cualquiera que sea el modo literal en que se enuncien, han de entenderse (...) como mandatos, orientaciones u objetivos, dirigidos a los poderes públicos autonómicos para el ejercicio de competencias que el Estatuto atribuya» - la cursiva es mía- (STC 247/2007, FJ 15.c). Llegados a este punto, el Tribunal recuerda que el art. 147.2 de la CE habilita al Estatuto de Autonomía para atribuir competencias a las Comunidades Autónomas y, en esta operación la norma institucional básica puede imponer a los poderes públicos autonómicos «de modo directo, criterios o directrices para su ejercicio o que lo hagan, de modo indirecto, mediante la formalización de enunciados o declaraciones de derechos a favor de los particulares. Se trata, en ambos supuestos, de mandatos al legislador y restantes poderes públicos autonómicos, imponiéndoles prescripciones que son vinculantes para los mismos con independencia de la veste de que se revistan. En todo caso, lo relevante es que dichos mandatos deberán estar conectados con una materia atribuida como competencia por el Estatuto y que, aunque vinculen efectivamente a los poderes públicos de la Comunidad Autónoma, necesitarán para adquirir plena eficacia del ejercicio por el legislador autonómico de la competencia normativa que le es propia, de manera que el principio o derecho enunciado carecerá de justiciabilidad directa hasta que se concrete, efectivamente, su régimen jurídico, pues sólo entonces se configurarán los consiguientes derechos subjetivos de los ciudadanos, al integrarse por dicho legislador las prescripciones constitucionales que han de ser necesariamente salvaguardadas (arts. 81.1 y $149.1 \mathrm{CE})^{33} »$ - la cursiva es mía- (FJ 15.c de la STC 247/2007).

disponible en la dirección electrónica: http://www10.gencat.net/eapc_revistadret/recursos_interes/especial\%20estatut/documents\%20especial\%20estatut/document.2010-07-15.7236299341/ca)

33 Argumentación de la que el magistrado V. CONDE discrepa en el voto particular que redacta a las SSTC 247/2007 y 31/2010. Igualmente, para G. FERNÁNDEZ FARRERES resulta «manifiestamente injustificada y arbitraria», ¿Hacia una nueva doctrina constitucional del Estado Autonómico? Comentario a la STC 247/2007, de 12 de diciembre, sobre el Estatuto de Autonomía de la Comunidad Valenciana, Civitas, Madrid, 2008, pág. 120. 
No le falta razón al Tribunal Constitucional al señalar que cuando el Estatuto se refiere a «derechos» no siempre se ajusta a lo que entendemos como tales, sino que «puede comprender realidades normativas muy distintas», en especial, mandatos a los poderes públicos (STC 31/2010, FJ 16), aunque también la formulación de máximos o de simples aspiraciones de carácter principial que, en cierto modo, empañan el significado y la finalidad de los contenidos de estas declaraciones estatutarias de derechos ${ }^{34}$, con el consiguiente riesgo de su banalización ${ }^{35}$. Y no puede negarse que estas disposiciones abundan en el Título I del Estatuto catalán (STC 31/2010, FJ 16), así como en otras normas estatutarias ${ }^{36}$.

Sin embargo, aún teniendo presente dicha consideración deberíamos diferenciar entre este tipo de normas con una formulación más cercana a un principio, de aquellas otras que encierran una remisión al legislador. Las primeras son las que podríamos identificar como derechos «en blanco» (i) y los segundos como derechos de configuración legal (ii).

En el primer grupo (i) podemos ubicar aquellos enunciados que a pesar de aparecer formulados como no puede identificarse en ellos ningún elemento propio de un derecho, ni siquiera un contenido cierto por lo que se hace complicado, en muchas ocasiones, visualizar su virtualidad de vincular a los poderes públicos a un contenido que ni siquiera el estatuyente es capaz de concretar ${ }^{37}$. Habrá de ser la ley la que, con un alto grado de creatividad y un amplísimo margen de discrecionalidad, convierta ese «espejismo» estatutario $^{38}$ en un auténtico derecho.

34 Así Álvarez Conde, E., Reforma constitucional y reformas estatutarias, Iustel, Madrid, 2007, pág. 367.

35 Castellá Andreu, J. M. a , «La incorporación de Cartas de derechos y deberes en los Estatutos de Autonomía de las Comunidades Autónomas», en Le fonte del diritto, oggi. Giornate di studio in onore di Alessandro Pizzorusso (Pisa, 3-4 marzo 2005), Edizione Plus, Pisa, 2006, pág. 357.

36 A modo de ejemplo puede citarse el caso de dos preceptos que aparecen en los Títulos relativos a los derechos en los Estatutos valenciano y balear. En el primero, se inserta una norma referida sector agrario valenciano para reconocerle su importante labor en la actividad productiva, en el mantenimiento del paisaje, del territorio, del medio ambiente, de la cultura, de las tradiciones y costumbres más definitorias de la identidad valenciana y así justificar el mandato a la Generalitat valenciana de adoptar medidas que garanticen los derechos de este sector, su desarrollo y protección, así como de los agricultores y ganaderos (art. 18). Y en el caso balear, el reconocimiento lo es a la actividad turística como elemento económico estratégico de las Illes (art. 24). También pueden traerse a colación los arts. 17 y 19 de los Estatutos valenciano y aragonés, respectivamente, con la proclamación del derecho al agua; los derechos que se proclaman en el ámbito de las nuevas tecnologías en los Estatutos andaluz (art. 34), valenciano (art. 19.2) y el proyecto de Estatuto de Castilla-La Mancha (art. 12.1.h) o, por último, del derecho a la solidaridad que acogen, con diversas formulaciones, los arts. 15 del Estatuto valenciano; 24 del Estatuto catalán; 21 del Estatuto balear y 18 del proyecto de Castilla-La Mancha.

37 Así ocurre con la formulación en algunos Estatutos con la proclamación genérica del derecho a vivir con dignidad, seguridad y autonomía, libres de explotación, de malos tratos, al libre desarrollo de su personalidad y a la capacidad personal que, algunos Estatutos reconocen a todas las personas: en especial, arts. 15 del Estatuto catalán y 12 del aragonés. El Estatuto catalán proclama, además, alguno de ellos como derechos específicos de determinados colectivos: mujeres, menores, discapacitados, etc.

38 Se utiliza la expresión de P. BigLino cuando se refiere a la tabla de derechos contenida en el Estatuto catalán cuyas definiciones, en muchas ocasiones «no se corresponden con lo previsto, con más detalle, en el resto de articulado». En opinión de esta autora, lo que aparece calificados como derechos en realidad se corresponden a «principios cuya eficacia jurídica depende de la legislación posterior o, todavía más, enunciados que, por desgracia, ni siquiera la ley puede asegurar, al menos a corto plazo». Ver «Los espejismos de la tabla de derechos», en Derechos, deberes y principios en el nuevo Estatuto de Autonomía de Cataluña, cit., págs. 49 y 50 . Término del que, además, se han hecho eco L. Aguiar de Luque, A. Gómez Montoro y J. J. Solozábal Echa- 
Sin embargo, por lo que se refiere al segundo grupo de derechos señalado (ii), debe reconocerse que, a diferencia de los anteriores, su formulación estatuaria se acompaña de un mínimo contenido remitiéndose, en todo lo demás, a lo que pueda disponer una ley de desarrollo. Es cierto, como recuerda el Tribunal, que su plena eficacia requerirá del legislador autonómico del ejercicio de las competencias normativas que les son propias «pues sólo entonces se configurarán los consiguientes derechos subjetivos de los ciudadanos» (FJ 15 c de la STC 247/2007).La alusión a la ley no debiera implicar la negación de la condición de derecho a las prescripciones contenidas en sus enunciados ${ }^{39}$. Aceptar tal consecuencia implicaría reconocer que la existencia de un derecho se somete a su capacidad para ser alegados o no directamente ante una instancia jurisdiccional ${ }^{40}$. Y no sería ocioso recordar que muchos de los derechos proclamados en la Constitución incorporan esa remisión al legislador sin que, por esta razón, se hayan visto menguados en su valor ni consideración como tales derechos constitucionales generando una eficacia directa por sí mismos y sin esperar a la intermediación legislativa que requería su plena operatividad ${ }^{41}$. Incluso, el hecho de que el estatuyente haya acogido buena parte de estos derechos con una explícita remisión a la ley, lejos de ser una connotación censurable constituyen un elemento positivo en la medida que permiten al futuro legislador ir adaptando el contenido y las condiciones de ejercicio de tales derechos al momento político, económico, cultural o social en el que hayan de actuarse, garantizándose, de esta manera, en su propia formulación el principio democrático.

\section{EL DESENLACE. DE LA ORIGINALIDAD DEL ESTATUYENTE A LA CREATIVIDAD DEL TRIBUNAL CONSTITUCIONAL: LA DESACTIVACIÓN NORMATIVA DE LAS CARTAS ESTATUTARIAS DE DERECHOS}

Asistimos a un proceso de lógicas confrontadas en el que la aparente originalidad del estatuyente es respondida por una desmesurada labor creativa por parte de un Tribunal Constitucional que ha exagerado su papel de intérprete supremo de la Constitución ${ }^{42}$, hasta el punto de arrogarse la condición de «poder constituyente prorrogado o sobrevenido» ${ }^{43}$. Así se demuestra por el hecho de acabar admitiendo la licitud constitucional de

VARRía en la encuesta sobre «Derechos Fundamentales. Estatutos de Autonomía y Derecho» que aparece publicada en Teoría y Realidad Constitucional, nº 20, 2007, págs. 31 a 40.

39 T. DE LA QUADRA-SALCEDO JANINI explica la capacidad de generar eficacia inmediata de estos derechos estatutarios en «El régimen jurídico de los derechos sociales estatutarios. Reflexiones tras la STC 247/2007, de 12 de diciembre», Revista General de Derecho Constitucional, nº 5, 2008, págs. 23-26.

40 Así también CÁmara, G., «Los derechos sociales estatutarios no han sido tomados en serio...», ob. cit., pág. 287.

41 Así Solozábal Echavarría, J. J., «Igualdad y Estado Autonómico», Anuario de la Facultad de Derecho de la Universidad Autónoma de Madrid, no 13, 2009, pág. 176.

42 Sobre este aspecto se centra especialmente el voto particular del magistrado J. RODRíGuEZ-ZAPATA a las SSTC 247/2007 y 31/2010. Igualmente este exceso «interpretativo» de Tribunal es censurado en los votos particulares emitidos por los magistrados V. Conde, J. Delgado y R. Rodríguez Arribas a la STC 31/2010.

43 FJ 57 de la STC 31/2010. Ésta es una afirmación que literalmente el Tribunal Constitucional realiza, a propósito de enjuiciar la definición de las categorías de competencias en el Estatuto catalán, pero que subyace 
estas declaraciones estatutarias de derechos al tiempo que se rechaza, en esencial, su valor como tales derechos. Esta argumentación que, de entrada, puede ser calificada de simple y, en cierto modo, incoherente, responde, en el fondo, a una alambicado propósito: negar la virtualidad de un Estatuto para crear o proclamar nuevos derechos al margen de lo establecido en la Constitución -interpretada de conformidad con lo dispuesto en su art. 10.2, la jurisprudencia del Tribunal Constitucional y el legislador estatal o autonómico, en virtud de la distribución de competencias. Es decir, la aceptación de estas cartas de derechos sólo puede realizarse si se entiende que las mismas no proclaman nuevos derechos al margen de la Constitución. Se abjura, de esta manera, de la tesis de que el Estatuto de Autonomía pudiera suplir o complementar la Constitución en este concreto ámbito ${ }^{44}$. Por tanto, todo aquello que no tiene conexión con los derechos constitucionales, a pesar de que el estatuyente los identifique como «derechos', son «desactivados» como tales y convertidos en meros principios de actuación o directrices de los poderes públicos autonómicos. Y si éstos no son considerados derechos no puede entenderse vulnerada ni la literalidad de la Constitución ni la función que la misma otorga y el Tribunal así lo considera- a los Estatutos de Autonomía.

Este modo de proceder del Tribunal Constitucional recuerda mucho, salvando todas las distancias y diferencias, al que su homónimo italiano utilizó en las sentencias 372, 378 y 379 , de 29 de noviembre de 2004 , dictadas cuando se estaba llevando a cabo el proceso de elaboración de los nuevos Estatutos de las Regiones ordinarias que exigía el revisado artículo 123 de la Constitución italiana tras las reformas de los años 1999 y $2001^{45}$. Bajo la apariencia de principios y objetivos de actuación regional, los nuevos Estatutos regionales incluyeron normas de las que podían deducirse derechos ${ }^{46}$. Todas ellas fueron declaradas por la Corte Constitucional desprovistas de cualquier valor normativo. De esta manera, entendía la Corte italiana, que «en los enunciados examinados, a pesar de formar parte de un acto-fuente, no puede serle reconocida ninguna eficacia jurídica, debiéndose colocar en un plano de las convicciones que expresan las diferentes sensibilidades políticas presentes en la comunidad regional en el momento de la aprobación del Estatuto». Ni siquiera el contenido de estas disposiciones en las que se proclamaban estos objetivos y mandatos de la Región «podían ser asimiladas a las denomi-

en todo el pronunciamiento contenido en la citada sentencia: «En su condición de intérprete supremo de la Constitución, el Tribunal Constitucional es el único competente para la definición auténtica —e indiscutiblede las categorías y principios constitucionales. Ninguna norma infraconstitucional, justamente por serlo, puede hacer las veces de poder constituyente prorrogado o sobrevenido, formalizando uno entre los varios sentidos que pueda admitir una categoría constitucional. Ese cometido es privativo del Tribunal Constitucional. Y lo es, además, en todo tiempo, por un principio elemental de defensa y garantía de la Constitución: el que la asegura frente a la infracción y, en defecto de reforma expresa, permite la acomodación de su sentido a las circunstancias del tiempo histórico» (el resaltado es mío).

44 Canosa Usera, R., «La declaración de derechos en los nuevos Estatutos de Autonomía», Teoría y Realidad Constitucional, nº 20, 2007, págs. 86-88 y 114.

45 Ver los estudios comparados que realizan ANGUITA Susi, A., «Naturaleza y alcance de las declaraciones estatutarias de derechos en España e Italia», Revista Española de Derecho Constitucional, nº 80, 2007, págs. 199220 y Rosado, C., «Los derechos en los Estatutos de Autonomía: una visión comparada de la jurisprudencia constitucional española e italiana», Revista General de Derecho Público Comparado, 3, 2008, págs. 1-20.

46 Para un análisis, en castellano, más pormenorizado de las disposiciones estatutarias así como de la problemática que en torno a las mismas se generó, me remito al trabajo de Rossi, E., «Derechos de libertad y Estatutos regionales. La situación italiana» en Aparicio, M. A. (Ed.) y Castellá, J. M. ${ }^{a}$ y Expósito, E. (Coords.), Derechos y Libertades en los Estados compuestos, Atelier, Barcelona, 2005, en especial vid. págs. 212 a 218. 
nadas normas programáticas de la Constitución, a las cuales, por su valor de principio le han sido reconocidas generalmente no sólo un valor programático en relación con la futura disciplina legislativa, sino sobre todo una función de integración y de interpretación de las normas vigentes». Lejos de reconocerles tal naturaleza, la Corte Constitucional las devalúa al considerar que no son ni prescriptivas ni vinculantes sino que quedan relegadas a cumplir una función «de naturaleza cultural o incluso política, pero ciertamente no normativa ${ }^{47}$. Se evitó la declaración de inconstitucionalidad de estas disposiciones no reconociéndoles un valor normativo. Desprovistas de eficacia jurídica no podían resultar lesivas ni a la Constitución ni a las competencias del Estado.

Al Tribunal Constitucional no le ha hecho falta despojar de fuerza normativa a estas disposiciones $^{48}$. En el Estado Autonómico español, a diferencia del sistema regional italiano, los Estatutos de Autonomía deben contener las competencias de las Comunidades Autónomas y la formulación de las mismas es lo que permite salvar la normatividad de estos preceptos: no cabe hacer referencia a derechos que no tengan conexión con el ámbito de las competencias que estatutariamente se asumen. Pero, aún teniendo esta vinculación, los derechos serán aceptados como contenido estatutario siempre y cuando se entiendan sólo como normas que determinan el ejercicio de esas competencias - rechazándose, por tanto, su vertiente subjetiva-.

Ahora bien, para llegar a esta consideración no puede afirmarse que el Tribunal no se haya mostrado un tanto errático y, en ocasiones, algo enredado en sus razonamientos. Por una parte, se considera que el Estatuto no es una norma idónea para regular «derechos fundamentales» y/o «constitucionales', pero se admiten que «otros derechos» puedan formar parte del contenido estatutario siempre y cuando tengan conexión con el contenido necesario y mínimo que exige la Constitución a esta norma institucional básica, es especial, las competencias. Y por la otra, aceptada la proclamación de derechos cuando éstos vayan referidos o proyectados en los ámbitos materiales de competencia autonómica, el Tribunal Constitucional considera, sin detenerse ni siquiera en la estructura normativa del precepto, que a pesar del nomen, éstos no son auténticos derechos, sino que operan como simples mandatos de la actuación de los poderes públicos autonómicos en el ejercicio de sus competencias. Sorprendentemente, el argumento que avala la legitimidad constitucional de estos derechos es el mismo que el que, a su vez, permite defenestrarlos a una condición de meros principios ${ }^{49}$. Condición que recuerda mucho al estatuto constitucional de los derechos contenidos en el Capítulo III del Título I de la CE.

47 FJ 2 de la sentencia 372/2004 —Estatuto de la Toscana; FJ 5 de la sentencia 378/2004 —Estatuto de Umbria- y FJ 2 de la sentencia 379/2004 —Estatuto de Emilia-Romaña. Para un análisis más pormenorizado de esta jurisprudencia de la Corte Constitucional italiana me remito al trabajo de A. D'ATENA, «I nuovi statuti regionali e i loro contenuti programmatici», Le Regioni, n 3-4, 2007, págs. 399-420 (su traducción en castellano fue publicada en la Revista General de Derecho Constitucional, n ${ }^{\circ}$ 9, 2007, págs. 1-15 con el título «Entre retórica y normatividad: a propósito de las disposiciones programáticas contenidas en los Estatutos de las Regiones italianas»).

48 R. CANOSA vaticinó que esta solución de la Corte italiana no era posible en España porque los Estatutos de Autonomía disponían expresamente la vinculación de los poderes públicos autonómicos a las disposiciones estatutarias que acogían derechos. En «La declaración de derechos en los nuevos Estatutos de Autonomía», cit., pág. 80.

49 Quizás tenga razón J. L. CASCAjo CASTRO cuando afirma que «el Tribunal no puede por menos de reconocer las normas estatutarias que contienen derechos y principios, aunque para ello se vea forzado a devaluar 
Todo lo anterior me suscita dos consideraciones de distinto alcance. La primera de ellas adquiere una relevancia en un plano más abstracto y es que el Tribunal, como ya he señalado, pone un especial empeño en consolidar una concepción estancada de los Estatutos de Autonomía en tanto que normas exclusivamente objetivas definidoras de las instituciones y las competencias. Esta obstinación le lleva a negar cualquier signo de evidencia evolutiva en la naturaleza objetiva de estas normas, pretendiendo alejar de ellas la sombra constitucional que se trataba de proyectar con la inclusión de estas cartas de derechos.

Nuevamente vuelve a emerger con fuerza el papel del Tribunal Constitucional de actor decisor de un proceso evolutivo que se ha movido y se mueve en un marco constitucional insuficiente y ambiguo. Este rol, en parte provocado y en parte arrogado, si bien ha estado hartamente justificado en las primeras décadas de vigencia de la Constitución, en la actualidad se concibe como excesivo, más cuando el Tribunal no resuelve el conflicto planteado, sólo lo desvía y neutraliza — distinguiendo de este modo, entre la validez y eficacia de las normas enjuiciadas ${ }^{50}$.

Conectada a esta última consideración, la segunda y, a mi juicio, mucho más significativa por las consecuencias que puede conllevar en futuros pronunciamientos, es la de utilizar una nueva técnica de interpretación conforme de los preceptos estatutarios para evitar su declaración de inconstitucionalidad: la sentencia interpretativa de desactivación. Por una parte, se admiten que integren la norma estatutaria como uno de sus contenidos posibles, pero, por la otra, no se conciben, en la mayoría de los casos, como verdaderos derechos. Es verdad que pueden seguir operando en el plano normativo que deriva del rango de la norma estatutaria - y deben ser, por tanto, aplicados para enjuiciar la actuación de los poderes públicos autonómicos-, pero lo harán con el valor y la eficacia de los principios rectores de la actuación de los poderes públicos cuya actuación será determinante para la individuación de verdaderos derechos en el ordenamiento autonómico.

Llegados a este desenlace se cierra el círculo argumentativo del Tribunal: el reconocimiento de derechos en el ámbito autonómico no corresponde al Estatuto en tanto que norma institucional básica. Sólo es posible en un plano infraestatutario o legal: será el legislador autonómico quien, en el ejercicio de sus competencias, convertirá los «mandatos» estatutarios en verdaderos derechos subjetivos. Lo que sucede es que, en el reparto de competencias no encontramos ámbitos materiales en los que el Estado no pueda intervenir, en última instancia, con títulos transversales u horizontales. Siendo así, cualquier actuación normativa del legislador autonómico estará «afectada» por una u otra norma estatal de carácter sectorial que incida o en el haz de facultades de este derecho, o en todo o parte de su régimen de ejercicio o los sujetos obligados por el mismo. Unido a

su contenido y atenuar su fuerza». Interpretación que, en opinión de este autor, «es de puro compromiso» advirtiéndose, por ello, que es una medida «abierta aún a un cambio, porque las soluciones de compromiso son siempre susceptibles de evolución, cuando se alteran los equilibrios en juego». En «Los derechos sociales, hoy», Revista catalana de Dret Públic, nº 38, 2009, pág. 25.

50 En un sentido similar, SolozÁbal EChavarría, J. J., «Igualdad y Estado Autonómico», cit., pág. 172. Este afán de suplir la Constitución por parte del Tribunal Constitucional es criticado por J. TAJADURA — siguiendo la doctrina de P. de Vega — en «El Tribunal Constitucional y las reformas estatutarias: a propósito de la Sentencia 247/2007 sobre el Estatuto de Autonomía de la Comunidad valenciana», en GArCía RocA, J. y Albertí, E. (Coords.), Treinta años de Constitución, Tirant lo Blanch, Valencia, 2010, págs. 229 y 230. 
la consideración de que la tutela jurisdiccional de estos derechos es, también competencia estatal — como así ha declarado el Tribunal en la STC 31/2010, queda muy claro el discreto significado y el escaso valor, en el plano normativo, de estas declaraciones estatutarias de derechos.

La doctrina contenida en las sentencias analizadas encierran otra de no poca trascendencia: los derechos, sean o no fundamentales, son una cuestión estatal. El Estado no puede dejar de involucrarse bien porque la Constitución le atribuye una serie de competencias que, en la práctica, hacen muy improbable la exclusiva implicación del legislador autonómico — excluyendo al estatal—, bien porque, desde la perspectiva internacional, es el único sujeto capaz de otorgar el consentimiento para que determinados derechos que puedan aparecer en el contexto internacional puedan ser recibidos en el orden interno.

En un momento como el actual en el que parece bastante improbable llevar a cabo una reforma constitucional del Título VIII, los intentos de las Comunidades Autónomas en dar un salto cualitativo en el proceso de consolidación del modelo territorial de Estado ha sido ciertamente neutralizados por un Tribunal Constitucional que no ha podido hacer más que llegar a una forzosa y forzada solución de consenso que pueda proyectarse en todos y cada uno de los nuevos Estatutos de Autonomía a pesar de la heterogeneidad que caracteriza el contenido de estas declaraciones de derechos.

TITLE: Bill of rigths? in the «Estatutos de autonomia». An analysis according to the Constitutional Court Judgments 247/2007 and 31/2010.

ABSTRACT: The resolution of the constitutional challenges of the Estatutos de Autonomia of Valencia and Catalonia seems to have settled the debate over the existence of bill of rights in such laws. Constitutional Court judgments 247/2007 and 31/2010, and the most recent December 16th, admit that the Estatutos de Autonomía may contain rights. But the careful reading of the legal basis of the judgments raises yet another important issue from a constitutional perspective: which is the value of these rights? By treating this topic we are addressing to different but complementary questions. The first one refers to the contents of this part of the Estatuto. For the Court these statutory rights are not fundamental rights, which can only be declared in the Constitution. And these are rights that also must be connected to the sphere of competence of the $C_{0-}$ munidad Autónoma and can only link the autonomous government. The second one, focuses on the true nature of these rights. The Court, while recognizing the existence of subjective rights in the Constitution, denied that status to rights that appear linked only to the competences, setting them up as mere guidelines for the performance of the autonomous government. In this case, the existence of the right, depends on the activity of the regional legislator. The conclusion is that, contrary to the Estatuto de Autonomia intention, the Court recognized for the effectiveness of a guiding principle to make the most of the rights that comprise the mere government mandates. The analysis of the judgments was found that the constitutionality of this new content is accompanied by a counterpart, its deactivation as rules of law.

RESUMEN: La resolución de los recursos de inconstitucionalidad contra los Estatutos de la Comunidad Valenciana y de Cataluña parece haber zanjado el debate sobre licitud de las declaraciones estatutarias de Derechos a la luz de la Constitución. Las sentencias 247/2007 y 31/2010 —y la más reciente de 16 de diciembre-admiten que los Estatutos de Autonomía puedan contener derechos. La detenida lectura de los fundamentos jurídicos de las citadas sentencias plantea, sin embargo, otro tema de gran importancia desde la perspectiva constitucional: ¿tienen algún valor estas cartas estatutarias de derechos? A este interrogante se da respuesta abordando dos cuestiones distintas aunque complementarias. La primera de ellas hace referencia al contenido de esta parte de la norma estatutaria. Para el Tribunal estos derechos estatutarios no son derechos fundamentales, los cuales sólo pueden ser proclamados en la Constitución. Y son derechos que, además, deben estar conectados al ámbito competencial de la Comunidad Autónoma y solo pueden vincular a los poderes públicos autonómicos. La segunda se centra en la verdadera naturaleza de estos derechos estatutarios. El Tribunal, a pesar de reconocer la existencia de derechos subjetivos en los Estatutos, niega tal condición a los derechos estatutarios que aparezcan vinculados solo a las com- 
petencias configurándolos como meros mandatos de la actuación de los poderes públicos autonómicos. La existencia del derecho, en este supuesto, dependerá de la actuación del legislador autonómico. La conclusión es que, contrariamente a lo querido por el legislador estatutario, el Tribunal les reconoce la eficacia de un principio rector al convertir la mayoría de los derechos que las integran en meros mandatos a los poderes públicos. El análisis de las citadas sentencias ha constatado que la licitud constitucional de este nuevo contenido estatutario viene acompañada de una contrapartida: su desactivación normativa.

KEY Words: Bill of rights in the Estatutos de Autonomia. Constitutional content of the Statute of Autonomy. Autonomic rights. Mandates the autonomic legislator. Deactivation rules.

Palabras Clave: Declaraciones estatutarias de derechos, Contenido constitucional del Estatuto de Autonomía. Dderechos estatutario. Mandatos al legislador autonómico. Desactivación normativa.

FECHA DE RECEPCIÓN: 8.01.2011. FeCHA DE ACEPTACIÓN: 26.01.2011 
